\title{
HISTOLOGICAL STUDIES OF THE DEVELOPMENT OF THE ALVEOLAR DENTAL LIGAMENT OF YOUNG RHESUS MONKEYS
}

\author{
By F. Hecker, B.S., D.D.S., A.M., M.I)., Kinsas (ity, Mo.

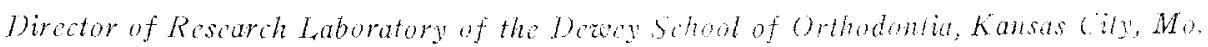

$\mathrm{H}^{\mathrm{t}}$ STOLOGICALLY the alveolar dental ligament and the periostem of the alveolus are alike. The author does not believe that without knowing the location of the field microscopically one can differentiate these tissues. A careful examination of slicles in the author's possession which are longitudinal sections. reveals no line of differentiation between the alveolar dental ligament and the periostenm, but instead shows that the periosteum and the alveolar dental ligament of the deciduous tooth are histologically the same. In addition to this observation, one also learns from the slides that the fibrous capsule which surrounds the developing tooth is also a tissue of the same type at the periosteum of the alveolus.

Anatomically let us trace the periosteum in its course from the alveolus. At the gingiva of the tooth, we observe that the periosteum passes acoss the space between the alveolus and the neck of the tooth and that some of the fibers of the periosteum are turned downwards. Directly below the gingiva we find the at veolus and the fibers of the alveolar dental ligament in this area take on a definite angle and this angle is maintained practically to the apical area of the root of the tooth. In the actual apical area of the root of the tooth are the fibers of the alveolar dental ligament; although some are attached to the root of the tooth. many of them are parallel to the root of the tooth and occasionally we note a bundle of fibers projecting out in the immediate alwohls.

Continuing our study of the alveolar dental ligament we learn that some of the fibers of the alveolar dental ligament in the apical area of the teciduous tooth unite with the fibrous capsule of the permanent woth. Thus, by this union of the fibers, we practically have a continuation of the fibers of the alveolar dental ligament of the decideous tonth with the filmous capsule, Just at what time the union takes place the author does not know and further it is not necessary, for this paper is not dealing in the early embryomal stages of the development of the alveolar dental ligament. Anatomically, the alveolar dental ligament is ligamentous. Other functions which the alveolat dental ligament possesses are that it is one of the avenues of vascularization of the alveolus in the arca with which it comes in contact and it is also one of the avenues of vasentarization of the cementum of the root of the tooth. From the foregoing statement the realer must not infer that the alveolar dental ligament is the only avenue of vascularization of the alveolus or the cementum; for the author does not believe it is. In addition 10 the foregoing functions of the alveolat dental liganent, it has the same role to the alveolus forming the root socket as the periosteum has for the bone; nanely, that it is a limiting membran for the alveolus. Likewise, the atveolar dental ligament is a limiting nembrane for the limiterl bony covering of the root of the tooth. 
Let us now commence the study of photomicrographs that show the root of the deciduous tooth, the alveolus, the alveolar dental ligament, the cementum, and the relative position of the cusp of the permanent tooth to the root of the deciduous tooth. In Fig. 1, at 1 is shown a Haversian canal of the alveolus; 2 , the alveolus; 3 , the alveolar dental ligament; 4 , the dentine; 5 , the cementum; 6 , the alveolar dental ligament covering the absorbing area of the deciduous root. At 7 is shown an area at which there is a separation of the fibrous capsule which surrounds the developing tooth; 8 shows an area, which, prior to decalcification, was partially occupied by the enamel of the crown of the developing tooth; 9 shows a small portion of the lymphoid pad and fibrous tissue which approximately

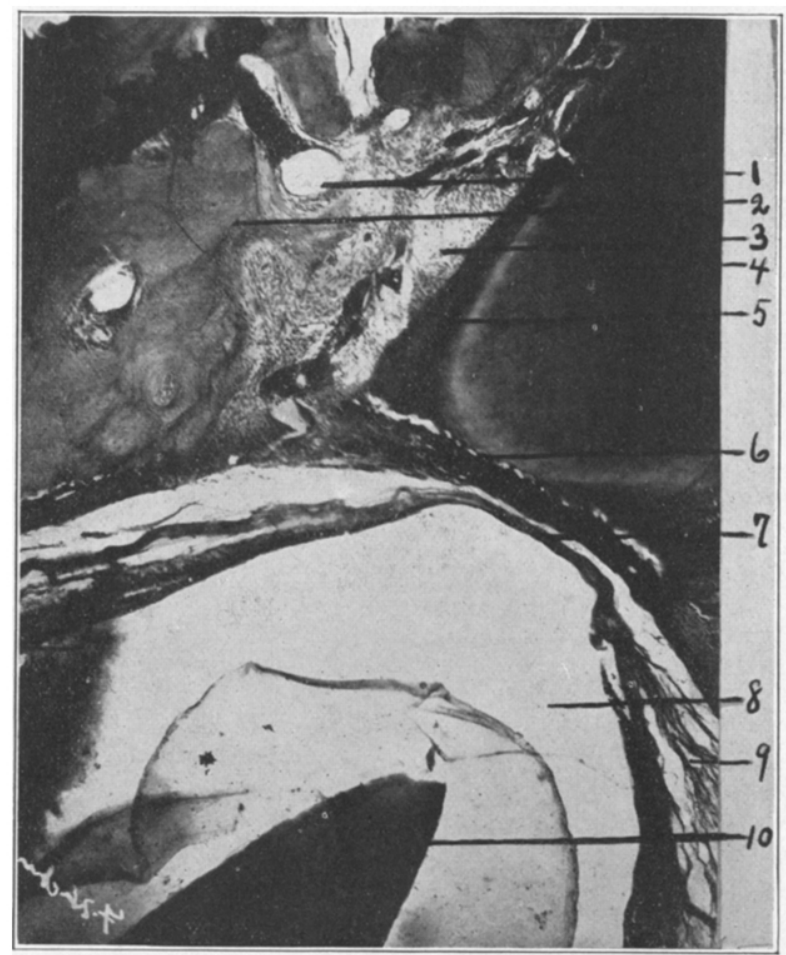

Fig. 1.--Showing the relative position of the root of the deciduous tooth and the crown of the permanent tooth and all of the immediate dental tiseties.

covers the cuspal portion of the developing looth; 10 is one of the cusps of a permanent premular.

This picture shows very excellently the position of the alveolar dental ligament of the deciduous tooth and also shows the position of the alveolar dental ligament covering the end of the root, and at 7 is shown the fibrous capsule which surrounds the developing permanent tooth. The fibrous capsule which surrounds the developing permanent tooth unites with the alveolar dental ligament of the deciduous tooth; for evidence upon which this statement is made, see Fig. 6 at 7 , and also Fig. 8 at 3 . Thus by this evidence with the low power of magnification, we learn that in the process of the development of the permanent tooth and the absorption of the deciduous tooth, the alveolar dental ligament and the periosteum 


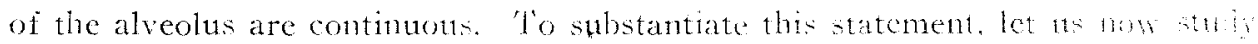
Fig. 2.

In Fig. 2 we observe at 1 the alveolus, at 2 a cominuation of the throus atp sule that surrounds the developing tooth, at 3 is shown the columnar epithelium covering of the fibrous capsule that faces the chamel of the leoth, and at thene Haversian canals are shown. This picture shows us the continuation of the same type of tissue as the periosteum of the alveolus of the alveolar dental higament that surrounds the root of the decidnens forth. Let $1 \mathrm{~s}$ now continue our study of the fibrous capsule which surround: the developing tooth in the next picture (Fig. 3) which shows the future singival attachment of the aiveolar dental ligament at the nock of the touth.

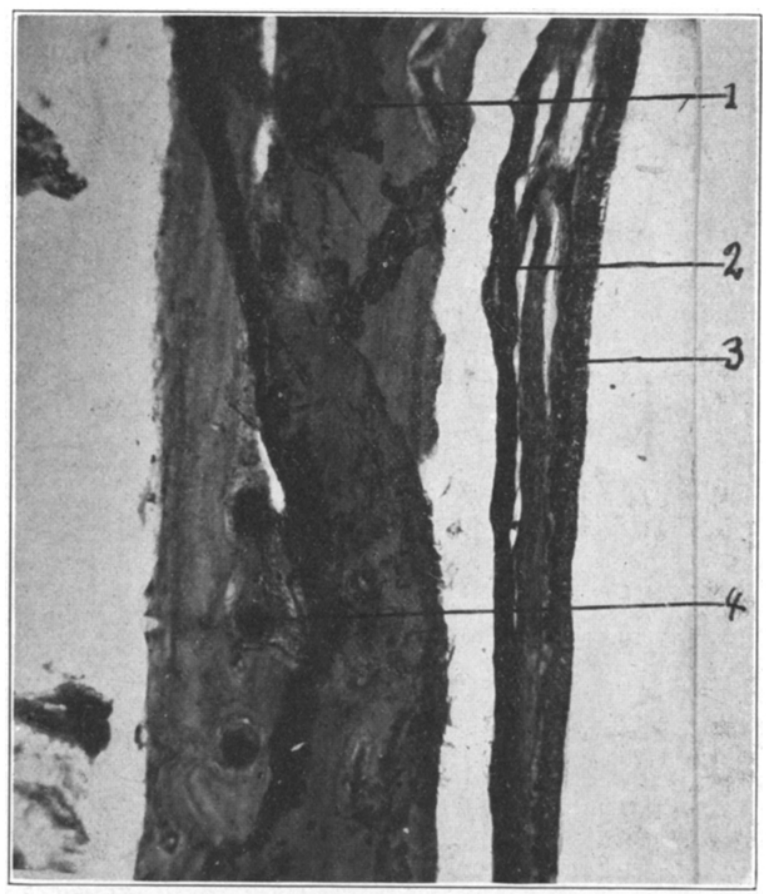

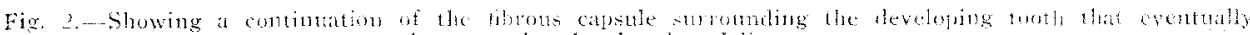
beomes the alveolar dental ligament

Beginning at 1 in Fig. 3 is shown the alveolus, directly below the pointing line 1 is shown a Haversian canat. At 2 is shown the further continnation of the fibrous tissue of the fibrous capsule; at 3 , the columnar epithelium covering of the fibrous tissue of the fibrous capsule which faces the enamel area of the developing tooth. At 5 is shown the incomplete attachment of the alveolar dental ligament of the future neck of the tooth of some of the fibers of the fibrous tissues composing the fibrous capsule. Lying directly to the left of this area one notes other fibers of the fibrous capsule which have separated from the bundle of fibers noted at 5 . At 6 is shown the dentine of the tubuli standing out in bold contrast. At 7 the odontoblasts are distinctly shown. and at 8 the blood vessels of the pulp of the tooth are shown. 
This picture shows very nicely the relative position of the fibrous capsule of the developing tooth which surrounds the crown. and its position at the future

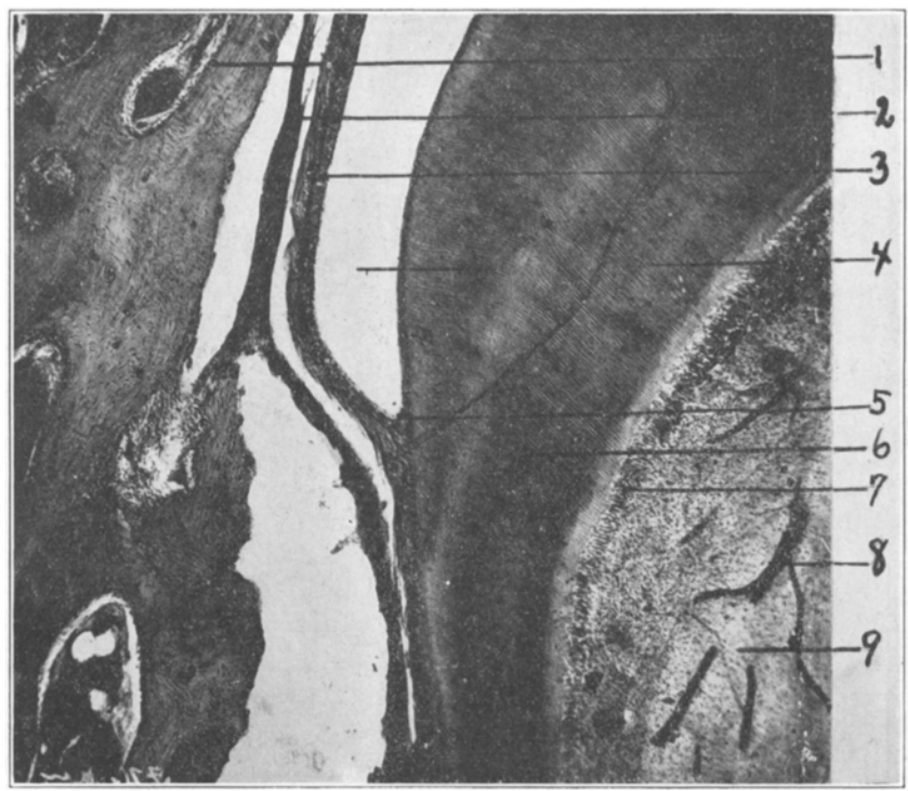

Fig. 3.- Showing the fibrous tissue of the fibrous capsule, the columnar epithelium, and the future neck of the tooth, and the attachment of some of the fibers of the fibrous capsule.

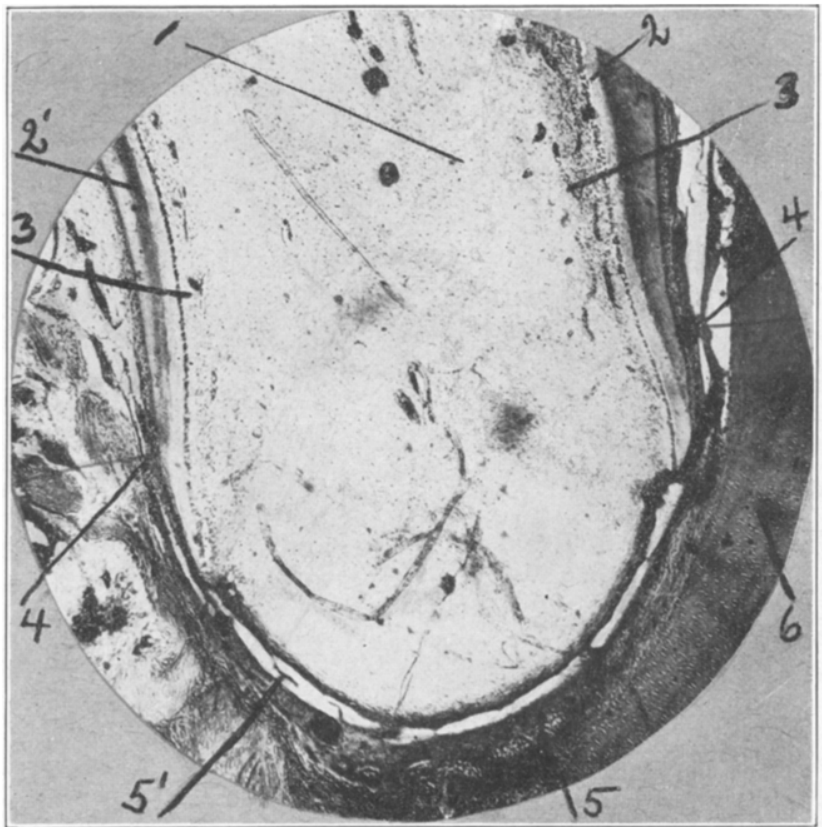

Fig. 4.-Showing the apical arca of a developing root of the tootl and the immediate dental tissues.

neck of the tooth. Histologically this tissue is the same as the periosteum of the alveolus or the alveolar dental ligament which surrounds the root of the deciduous tooth. 
In the next picture, (Fig. 4 ) is shown the extreme apical area of the root of a developing premolar. Beginning at 1 the pulp of the tooth is shown: 2 and $2^{\prime}$ are the dentine; 3 and $3^{\prime}$ show the odontoblasts; 4 and $4^{\prime}$ show the fibrous capsule surrounding the developing root, and at 5 and 5 the fibrous capsule at the extreme apical area of the developing root of the tooth; 6 is the alveolus.

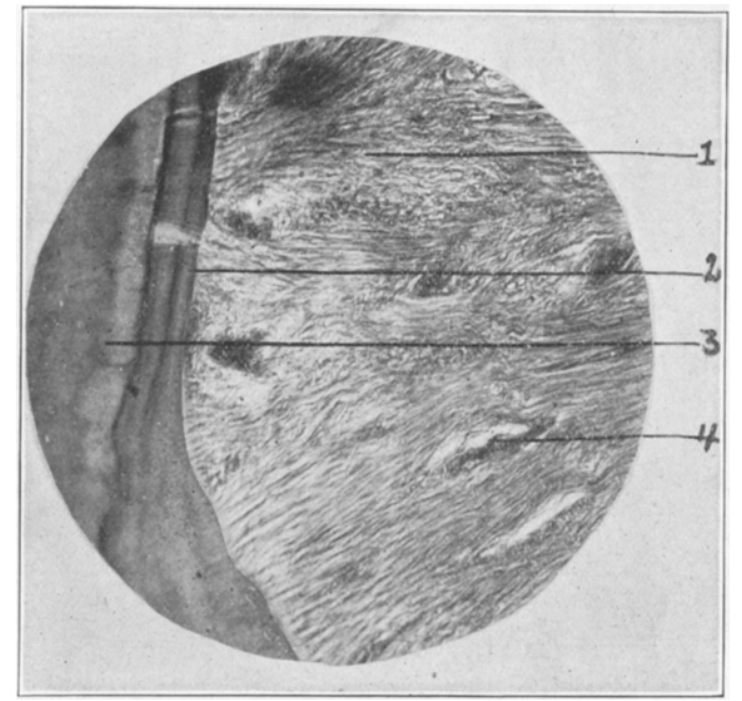

Fig. 5.- Showing the libers of the periosteme and alveolat dental ligament.

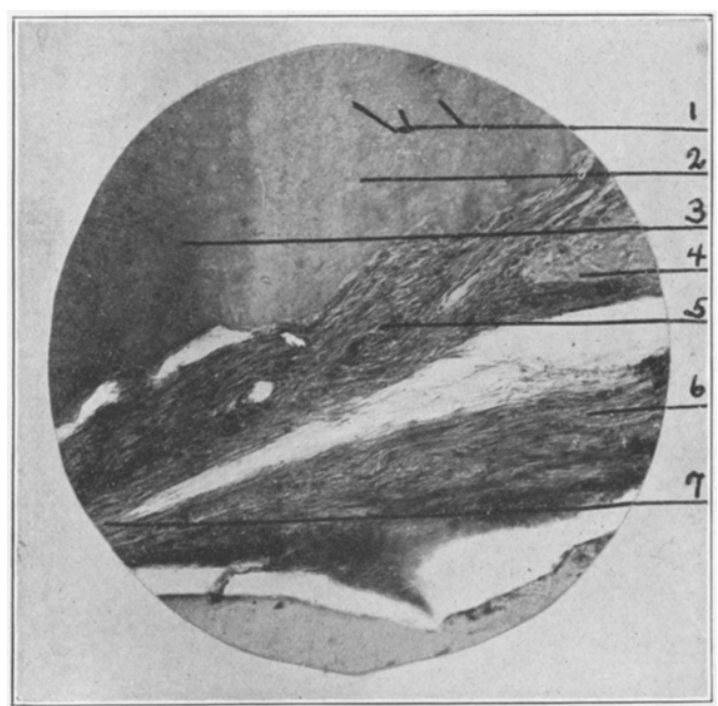

Fig. 6.--Showing the point of nuion of the alveolar dental liganemt and the fibrous cafsule which strounds the developing permanent tooth.

This picture shows that the alveolar dental ligament and the fibrous capsule which surrounds the developing tooth are continuous to the extreme apical area of the developing root of the tooth. Thus, from the foregoing pictures, we learn that the periosteum covering the alveolus is continued at this time in the develop- 
ment of the root of the tooth in the young rhesus monkey to the apical area of the developing tooth.

Having shown the foregoing pictures of low power, let us now study some photographs which are of a higher magnification. In Fig. 5 is shown an area in the immediate vicinity of the gingivus of the deciduous tooth. Beginning at 1 is shown an area, the fibers which are the direct continuation of the periosteum of the alveolus; at 2 , is shown the cementum of the deciduous tooth; at 3 , the cementum of the root of the deciduous tooth; at 4, cross section of a blood vessel in the substance of the alveolar dental ligament; directly below at 4 , is shown an area in which one notes that the fibers of the periosteum are turned at an angle, and it is at this point that the author no longer terms the tissue the periosteum, but instead-the alveolar dental ligament. Histologically the structure of the tissue is the same as the periosteum.

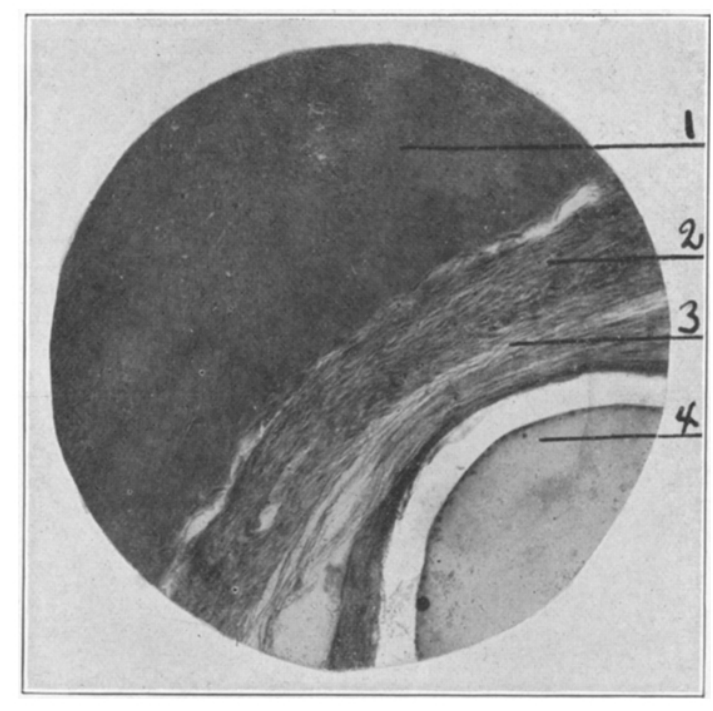

Fig. 7.- Showing an area in which the fusion of the alveolar dental ligament and the fibrous capsule surrounding the alveolar dental ligament is complete.

In the next picture, which is a continuation of the fibers shown in Fig. 5, is shown an area at the end of the noot of the deciduous tooth. Beginning at 1 , we observe the lacunæ of the cementum of the deciduous tooth; at 2 , the cementum ; at 3 , the dentine; at 4 , the alveolus; at 5 , the alveolar dental ligament of the deciduous tooth; at 6 , an area presenting the fibrous capsule which surrounds the developing tooth; and at 7 , is shown the point of union of the alveolar dental ligament of the deciduous tooth and the fibrous capsule which surrounds the developing tooth.

In this next picture we are bearing out a previous statement, and the evidence being a photograph, we must at this time accept the previous statement. In the next picture, which is a continuation of Figs. 5 and 6 , is shown a field in which the fibrous capsule and the alveolar dental ligament are one and the same tissue microscopically and anatomically.

Beginning at 1 , which is the dentine in the deciduous tooth, and advancing to 
2 , is shown the alveolar dental ligament of the deciduous tonth. At 3 is shown an area in which the tusion of the tissues is complete while at 4 a slight separa. tion is noted. 'Mhis separation of the tisstes is the result of the pulling apart of

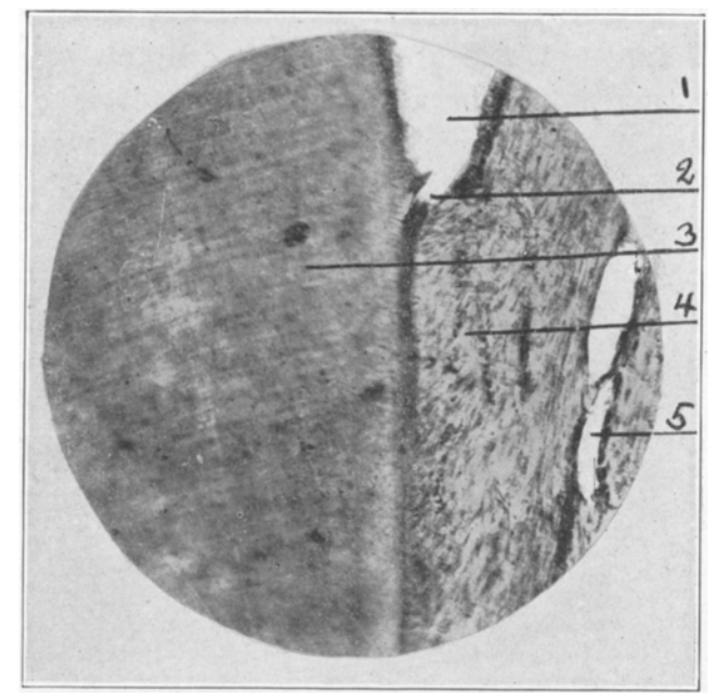

Jix. S.--Showing the funte gingivus of the developing permanent tanth.

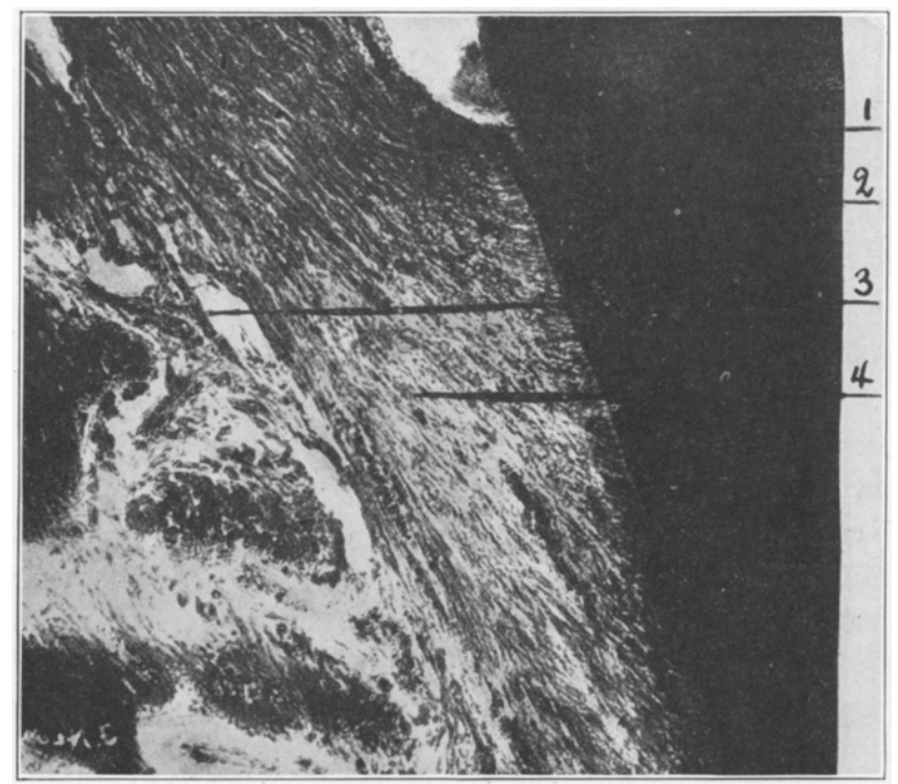

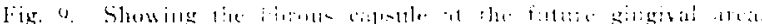

the tissues, and at 5 is shown the space which is occupied by the enamel of the permanent tooth.

In Fig. 7 we have substantial evidence that the fibrous tissue of the capsule which surrounds the develepping permanem lowh is of the type known histo- 
logically as the periosteum of the alveolus; and further, that the tissue is a continuation of the periosteum.

In the next picture (Fig. 8) is shown a field which presents the future neck of the permanent tooth and also its gingivus. At 1 we note the area occupied by the enamel; 2 is the future gingivus and point of attachment to the periosteum ; 3 is the dentine; 4 is the alveolar dental ligament, 5 is the alveolar border of the alveolus.

In the next picture (Fig. 9) is shown a higher magnification of the same field as shown in Fig. 8. At 1 is shown the future gingival attachment of the periosteum; at 2 is shown the cementum, and directly to the left of the heavy shaded cementum, some cemental cells are shown. This row of cells can be traced by careful focusing to the extreme apical area of the developing tooth. At 3 is shown the alveolar border; at 4 , the future alveolar dental ligament.

From the foregoing pictures we learn that the alveolar dental ligament of the tooth and the periosteum of the alveolus are histologically the same in type; and that the alveolar dental ligament is a direct continuation of the periosteum into the root socket; and, further, that the fibrous capsule which surrounds the developing permanent tooth is a direct continuation of the alveolar dental ligament of the deciduous tooth, and, therefore, the fibrous capsule is a continuation of the periosteum. We also learn that the function of the alvcolar dental ligament is that of a ligament, also that it is a limiting membrane, and that it is not concerned in the development of the cementum or the alveolus directly. But, as previously stated, it limits the growth of the cementum of the root of the tooth and the alveolus that forms the root socket.

\title{
TREATMENT OF A CASE OF EXTREME MAXILLARY MALFORMATION IN ADULT LIFE
}

\author{
By L. J. Huber, D.D.S., St. GeNevieve, Mo.
}

$\mathrm{F}$

IGURE 1 represents the unfortunate condition of a lady who was permitted to reach adult life with an extreme type of maxillary malformation and labioversion of the upper incisors. This condition seriously impaired the normal masticatory function in its initial stage and resulted in a repulsive type of facial deformity, with the central incisors exposed and a marked eversion of the lips.

Properly administered orthodontic treatment in her youth, would have arrested the malformation and corrected the malocclusion and the accompanying facial deformity. In reply to her repeated inquiries, the presumably authoritative, though unscrupulous, advice was, that she would outgrow her deformity in a few years. In this instance the patient had to learn through bitter experience, as many others have, the truth of the statement that, "Malocclusion and its accompanying deformities grow steadily worse; nature and time rarely exercise a corrective influence," as Lischer points out in his admirable book, "Orthodontics." 